Aída Cristina do Nascimento Silva 1

Ricardo Silveira Bernardes 2

Luiz Roberto Santos Moraes 3

Joana D'Arc Parente dos Reis 4

\section{Critérios adotados para seleção de indicadores de contaminação ambiental relacionados aos resíduos sólidos de serviços de saúde: uma proposta de avaliação}

\author{
Criteria for definition of environmental \\ contamination indicators related to solid \\ waste from health care facilities: a proposal \\ for evaluation
}

1 Centro Nacional de Epidemiologia, Coordenação Geral de Vigilância Ambiental em Saúde, Fundação Nacional de Saúde, Ministério da Saúde. SAS, Quadra 4, Bloco N, 7 o andar, Sala 712 , Brasília, $D F$ 70058-902, Brasil. aida.silva@funasa.gov.br. 2 Departamento de Engenharia Civil e Ambiental, Faculdade de Tecnologia, Universidade de Brasília. Av. L3 Norte 606, Brasília, DF 70910-900, Brasil.

3 Departamento de Hidráulica e Saneamento, Escola Politécnica, Universidade Federal da Bahia. Rua Aristides Novaes 2, Salvador, BA 40210-630, Brasil. 4 Núcleo de Biologia de Alimentos e Ambiente, Gerência de Controle de Qualidade de Produtos e Ambiente, Laboratório Central de Saúde Pública. Av. L2 Norte 601, Brasília, DF 70830-010, Brasil.

\begin{abstract}
The objective of this study was to identify target microorganisms as indicators of environmental contamination. The study evaluates the main environmental aspects and epidemiological chain related to such agents. Microorganisms were selected through key information about microbiological characterization of health care facilities' solid waste and evaluation of risk of infection from discarded sharps. The form of evaluation proposed for criteria adopted in the selection of contamination indicators included prior submission of a structured questionnaire to a network of specialists from the Federal District of Brazil. The specialists' multidisciplinary background, including professionals from the health field and an environmental microbiologist, helped define environmental contamination indicators by consensus. Pathogens such as Mycobacterium tuberculosis and hepatitis A and B viruses were specifically identified as capable of environmental survival or resistance.
\end{abstract}

Key words Contamination; Solid Wastes; Medical Waste; Pollution Indicators

Resumo O objetivo deste estudo é identificar microrganismos indicadores de contaminação ambiental, a partir dos principais aspectos ambientais e cadeia epidemiológica relacionados aos agentes. A seleção dos microrganismos a serem definidos como indicadores foi realizada a partir de informações específicas sobre a caracterização microbiológica de resíduos sólidos de serviços de saúde (RSSS), e a avaliação de riscos de infecção pelos materiais perfurocortantes presentes nesses resíduos. A forma de avaliação proposta para os critérios adotados na seleção de indicadores de contaminação abrangeu entrega prévia de questionário estruturado a uma rede de especialistas do Distrito Federal. A formação multidisciplinar dos especialistas, composta por profissionais da área de saúde e microbiologista ambiental, permitiu definir, de forma consensual, os indicadores de contaminação ambiental. Patógenos como Mycobacterium tuberculosis e os vírus da Hepatite A e B destacam-se no estudo com capacidade de sobrevivência ou resistência ambiental.

Palavras-chave Contaminação; Resíduos Sólidos; Resíduos de Serviços de Saúde; Indicadores de Contaminação 


\section{Introdução}

A crescente consciência sobre os riscos à saúde pública e ao meio ambiente, provocados por resíduos sólidos gerados nos serviços de saúde (RSSS), deve-se, principalmente, as suas frações infectantes. Surpreendentemente, no Brasil, há mais de 30 mil unidades de saúde produzindo esses resíduos, e na maioria das cidades, a questão do manuseio e da disposição final não está resolvida, e acrescenta-se que algumas unidades de saúde desconhecem a quantidade e a composição dos resíduos que produzem (Ferreira, 1995).

Em alguns municípios e grandes centros urbanos brasileiros, a dúvida sobre a periculosidade dos RSSS levam à implementação de sistemas diferenciados específicos, desde as usinas de incineração até a utilização das técnicas de disposição final de resíduos infectantes no solo.

Ampliando as discussões sobre os riscos associados aos RSSS, trabalhos científicos confirmam o reconhecimento dos riscos desses resíduos, pela sobrevivência de agentes dotados de elevada resistência às condições ambientais. Suberkeropp \& Klugg (1974, apud, Morel \& Bertussi Filho, 1997), identificaram importantes patógenos nos resíduos sólidos. Nessa pesquisa, a Mycobacterium tuberculosis apresentou um tempo de resistência ambiental de até 180 dias na massa de resíduos sólidos. De forma a destacar outras características peculiares de agentes biológicos na presença de RSSS, Hirai (1991) apresenta a resistência à dessecação da enterobactéria Escherichia coli, com possibilidade de causar infecção, na presença de proteínas derivadas de fluidos corpóreos (sangue e derivados). Em outro recente estudo sobre RSSS, realizado pela Associação de Pesquisa Japonesa, apresentando o estágio ambiental de patógenos nesses resíduos, foi demonstrada a possibilidade de sobrevivência da dose infectante do vírus da Hepatite B ou C, durante uma semana, em uma gota de sangue retirada de uma agulha hipodérmica (Pruss et al., 1999).

Desse cenário de avaliação de risco, envolvendo algumas frações específicas dos RSSS, há consideração de outros possíveis mecanismos de sobrevivência de patógenos na massa desses resíduos, como por exemplo, os materiais biológicos contaminados que podem se constituir em importantes veículos para os microrganismos produtores de doenças, quando não devidamente manuseados ou tratados adequadamente.

Além do que, no aspecto epidemiológico a compreensão de doenças infecciosas causadas pelos RSSS, não pode ser definida apenas pela comprovação microbiológica, sem levar em conta outros fatores como via de transmissão adequada, porta de entrada e hospedeiro em estado de suscetibilidade (Rutala et al., 1989).

Entretanto, no contexto nacional, as opiniões divergentes sobre o risco de periculosidade dos RSSS, na sua maioria, são direcionadas à ausência de fatos que comprovem que esses resíduos causam doenças nas pessoas que desenvolvem atividades nos serviços de saúde (Zanon, 1990). Por outro lado, a literatura relata a importância de riscos infecciosos associados aos RSSS, principalmente aos materiais perfurocortantes, como principal perigo à saúde ocupacional (Collins \& Kennedy, 1987; Ferreira, 1995; Phillips, 1999; Turnberg \& Frost, 1990). Collins \& Kennedy (1987) apresentam que a adoção de precauções mais criteriosas referente aos materiais perfurocortantes, devese à grande possibilidade da transmissão de doenças (Hepatite B), por meio do contato com o sangue contaminado do que as enfermidades de origem aerógena.

Visando contribuir para avaliação de riscos associados aos RSSS, este estudo procurou identificar fatores ambientais específicos relacionados aos microrganismos patogênicos, presentes nas frações infectantes desses resíduos, buscando aprofundar conhecimentos favoráveis à persistência ambiental dos agentes e suas infectividades. As características ambientais de destacados patógenos, favorece, inclusive, a definição dos microrganismos indicadores de contaminação ambiental.

Além do mais, as importantes vias de transmissão de doenças e mecanismos de penetração no hospedeiro, utilizados por alguns dos microrganismos patogênicos em estudo, servirão de referência para reflexões sobre o desenvolvimento de riscos à saúde pública e ao meio ambiente, relacionadas aos materiais biológicos contaminados existentes nos RSSS, bem como contribuir, de certa forma, para avaliações associadas à periculosidade desses resíduos, quando mal gerenciados, ou mesmo na sua disposição final no solo sem critérios adequados.

\section{Metodologia}

O presente trabalho representa parte de pesquisa sobre a identificação e a avaliação dos aspectos ambientais e a cadeia epidemiológica, relacionados aos microrganismos patogênicos presentes nas frações infectantes de RSSS.

O processo metodológico proposto, baseado no Método de Apoio à Decisão, permite a 
obtenção de dados específicos e informações qualificadas, associados à situação complexa em estudo, sob a previsão de julgamentos individuais entre os vários atores ou especialistas, de diferentes disciplinas, de forma a auxiliar na avaliação das particularidades do problema.

Em função desses aspectos relacionados ao citado método, além do tempo exíguo para a realização da pesquisa, foi utilizada na metodologia de trabalho, uma das alternativas do Método de Apoio à Decisão, que é a Técnica do Grupo Nominal.

A execução dos trabalhos pela Técnica do Grupo Nominal ocorre num exercício face-a-face, permitindo discussões mais amplas e com maior rapidez, além do número reduzido de participantes ou membros, de cinco a nove (Goicoechea et al., 1982; Tommasi, 1994). Em contrapartida, a Técnica do Grupo Nominal apresenta algumas desvantagens, dentre as quais, questões de custo, tempo, disponibilidade de participantes e até de natureza política (Tommasi, 1994).

Na seleção dos participantes, denominados também de especialistas, a reunião de conhecimentos práticos adquiridos pela experiência profissional e, por estarem relacionados à área de estudo ou análise do problema, foi um dos pré-requisitos para a formação da rede interativa de comunicação.

Para cumprimento do processo metodológico participaram, nesta etapa da pesquisa, cinco profissionais que atuam na área de infectologia, epidemiologia e microbiologia ambiental. A composição do grupo de trabalho buscou atender o número mínimo de participantes, estabelecido na aplicação da Técnica de Grupo Nominal, para obtenção de resultados qualificados no processo consensual de avaliação. Esses profissionais ou especialistas são provenientes de instituições como Hospital Universitário de Brasília da Universidade de Brasília (HUB/UnB), Fundação Nacional de Saúde (FUNASA) do Ministério da Saúde (MS), Laboratório Central de Saúde Pública (LACEN/DF) e Faculdade de Agronomia e Veterinária da UnB.

A formação multidisciplinar dos especialistas, constituída por médicos com experiência em serviços de controle de infecção hospitalar e doenças infecciosas e parasitárias; enfermeira com conhecimentos em mecanismos de propagação de doenças relacionadas à água e aos alimentos; biomédica e microbiologista com especialidade na área de microbiologia ambiental, favoreceu o processo de avaliação consensual sobre os critérios adotados na seleção dos indicadores.

O trabalho desta etapa foi iniciado a partir da entrega prévia de questionário estruturado aos especialistas, para análise e valoração dos critérios relacionados à identificação dos indicadores de contaminação ambiental. Salientase que a seleção dos indicadores, foi elaborada a partir das principais características ambientais e cadeia epidemiológica, relacionadas aos diferentes agentes patogênicos e levantamento bibliográfico continuado.

Ressalta-se também, que na metodologia de pesquisa, os especialistas puderam contribuir no julgamento das questões para reformulação ou alteração das informações disponibilizadas, com opiniões fundamentadas em argumentações técnicas ou razões científicas criteriosas.

No grupo de patógenos, a serem avaliados como indicadores, destacam-se as bactérias E. coli, Pseudomonas aeruginosa, Clostridium (botulinum e perfringens), Enterococos (ou Streptococcus faecalis), Staphylococcus aureus, M. tuberculosis e os vírus da Hepatite A e B.

A escolha dos microrganismos patogênicos foi realizada a partir de revisão da literatura sobre o assunto, sendo utilizadas informações específicas sobre caracterização microbiológica de RSSS (CETESB, 1983; Haas et al., 1996; Silva, 1993), e avaliação de riscos de infecção pelos materiais perfurocortantes presentes nesses resíduos (Collins \& Kennedy, 1987; Pruss et al., 1999; Turnberg \& Frost, 1990).

Destaca-se que na avaliação dos critérios propostos, para cada ambiente físico, deve-se associar os Critérios B (ocorrência no ambiente físico), C (forma ou estágio de resistência ambiental) e D (mecanismo de transmissão) com fatores de risco ambiental relacionados aos microrganismos indicadores. Os Critérios A e E estão associados, respectivamente, às características do agente e a avaliação quanto ao risco individual determinada por esses patógenos.

No procedimento da coleta de informações, de forma interativa entre os participantes, foi utilizada o instrumento metodológico Matriz de Valoração -, e buscou-se identificar os critérios mais importantes na seleção dos indicadores. Esse instrumento auxiliou na avaliação consensual entre os especialistas, para a definição dos microrganismos patogênicos com maior significância em relação aos fatores de risco ambiental e individual.

O nível de importância para avaliação dos critérios foi estabelecido numa escala de sete gradações (peso), assim definidas: 0 - sem importância alguma ou nulo, 1 - quase sem importância, 2 - pouco importante, 3 - médio, 4 importante, 5 - muito importante e 6 - importantíssimo.

A escala proposta teve como objetivo destacar os indicadores de maior ou menor impor- 
tância na contaminação ambiental, sendo que para isso os especialistas tiveram como atribuição distribuir adequadamente a importância (peso) associada aos critérios.

\section{Resultados}

A Tabela 1 apresenta algumas doenças relacionadas aos microrganismos patogênicos presentes nos RSSS, classificando-os segundo a etiopatogenia das infecções. Pelos dados observados, verifica-se que a ocorrência de doenças infecciosas, associada a esses resíduos, deve-se a agentes encontrados na microbiota normal humana (patógenos secundários), e pató- genos que não são encontrados permanentemente em hospedeiros hígidos (patógenos primários).

A Tabela 2 apresenta a forma ou estágio de resistência ambiental de alguns dos microrganismos patogênicos em estudo, e respectivas doses infectantes. A análise da importância dessas informações permite identificar os agentes biológicos que resistem fora do organismo do hospedeiro, com possibilidade futura de infectar um indivíduo suscetível.

A descrição e valoração dos critérios a serem adotados para a definição de microrganismos indicadores de contaminação no ar, água e solo são apresentados, respectivamente, nas Tabelas 3, 4 e 5 .

Tabela 1

Características dos microrganismos patogênicos.

\begin{tabular}{|c|c|c|}
\hline Grupo de microrganismos & Etiopatogenia & Doenças \\
\hline \multicolumn{3}{|l|}{ Bactérias } \\
\hline Escherichia coli & Patógeno secundário & Infecções do trato urinário \\
\hline Pseudomonas aeruginosa & Patógeno secundário & Infecção respiratória, urogenital e de ferimentos \\
\hline $\begin{array}{l}\text { Clostridium sp. } \\
\text { (exceto perfringens) }\end{array}$ & Patógeno primário & Botulismo, tétano, gangrena gasosa \\
\hline Enterococos & Patógeno secundário & Infecções urinárias \\
\hline Staphylococcus aureus & Patógeno secundário & Pneumonia, septicemia*, furúnculo, carbúnculo** \\
\hline Mycobacterium tuberculosis & Patógeno primário & Tuberculose \\
\hline \multicolumn{3}{|l|}{ Vírus } \\
\hline Hepatite A & Patógeno primário & Inflamação do fígado \\
\hline Hepatite B & Patógeno primário & Inflamação do fígado \\
\hline
\end{tabular}

* Doença sistêmica causada pela invasão e multiplicação de microrganismos patogênicos na corrente sangüínea.

** Caracterizado por ser um estágio mais elevado da doença e formar um conjunto de tumores.

Tabela 2

Formas de resistência ambiental na transmissão de doenças.

\begin{tabular}{lll}
\hline Microrganismos patogênicos & Forma ou estágio de resistência ambiental & Dose infectante1 \\
\hline Escherichia coli & Resistência à dessecação & $10^{6}-10^{8}\left(\right.$ UFC) ${ }^{2}$ \\
Clostridium perfringens & Formação de esporos & $10^{8}-10^{9}$ organismos $^{3}$ \\
Enterococos & Formato de "coccus" & $10^{-1010}($ UFC) \\
Staphylococcus aureus & Formação de aerossóis secundários & $<10-6$ g (de enterotoxina) 3 \\
Mycobacterium tuberculosis & Formação de aerossóis secundários & 1 a 2 bacilos (TI) \\
Hepatite B & Resistência em qualquer superfície seca & $0,00004 \mathrm{ml}$ (sangue total) (TSC)
\end{tabular}

UFC = Unidade formadora de colônia; TI = Tuberculose-infecção; TSC = Transmissão por sangue contaminado

1 Quantidade do agente etiológico necessária para iniciar uma infecção.

2 Cepas patogênicas e dados relacionados à veiculação do agente em alimentos.

3 Quantidade de organismos necessária para toxinfecção alimentar.

4 Dose relacionada à presença do agente no solo podendo resultar em provável doença. 
Avaliação dos critérios adotados na seleção dos indicadores de contaminação ambiental (ambiente físico - ar).

\begin{tabular}{|c|c|c|c|}
\hline $\begin{array}{l}\text { Indicador de } \\
\text { contaminação } \\
\text { ambiental }\end{array}$ & $\begin{array}{l}\text { Critério } \\
\text { (importância) }\end{array}$ & Descrição do critério & $\begin{array}{l}\text { Importância do } \\
\text { critério (peso) }\end{array}$ \\
\hline \multirow{6}{*}{$\begin{array}{l}\text { Mycobacterium } \\
\text { tuberculosis }\end{array}$} & A & Patógeno primário: ausência na microbiota normal humana & 2 \\
\hline & $\mathrm{B}$ & Contaminação aerógena & 6 \\
\hline & $\mathrm{C} 1$ & Formação de aerossóis secundários $\Rightarrow$ Resistência à dessecação rápida & 5 \\
\hline & $\mathrm{C} 2$ & Resistência a substâncias químicas $\Rightarrow$ Alterações nas suas características e resistência múltipla & \\
\hline & $\mathrm{D}$ & Aerossóis e poeira & 6 \\
\hline & $E$ & Mecanismo de penetração no hospedeiro: inalação (principal) & 6 \\
\hline \multirow{6}{*}{$\begin{array}{l}\text { Staphylococcus } \\
\text { aureus }\end{array}$} & A & Patógeno secundário: presença na microbiota normal humana & 2 \\
\hline & B & Contaminação aerógena & 3 \\
\hline & $\mathrm{C} 1$ & Formação de aerossóis secundários $\Rightarrow$ Resistência à dessecação rápida & 5 \\
\hline & $\mathrm{C} 2$ & Resistência a antibióticos $\Rightarrow$ Alterações nas suas características e resistência múltipla & \\
\hline & $\mathrm{D}$ & Aerossóis e poeira & 4 \\
\hline & $E$ & Mecanismo de penetração no hospedeiro: inalação (possível) & 4 \\
\hline \multirow{6}{*}{$\begin{array}{l}\text { Clostridium } \\
\text { botulinum }\end{array}$} & A & Patógeno primário: ausência na microbiota normal humana & 2 \\
\hline & B & Contaminação aerógena & 3 \\
\hline & $\mathrm{C} 1$ & Capacidade de esporulação $\Rightarrow$ Resistência à dessecação rápida e maior permanência no ambiente & 4 \\
\hline & $\mathrm{C} 2$ & Não apresenta resistência a substâncias químicas & \\
\hline & $\mathrm{D}$ & Os esporos presentes no solo podem ser suspensos e serem veiculados através de poeiras & 3 \\
\hline & $E$ & Mecanismo de penetração no hospedeiro: inalação (possível) & 2 \\
\hline
\end{tabular}

Critério: $A=$ Característica do agente, $B=$ Ocorrência no ambiente físico, $C=$ Forma ou estágio de resistência ambiental, D = Mecanismo de transmissão, E = Risco Individual. Importância (peso): 0 = Sem importância alguma ou nulo, 1 = Quase sem importância, 2 = Pouco importante, 3= Médio, $4=$ Importante, 5 = Muito importante, 6 = Importantíssimo.

\section{Discussão}

Pelos resultados apresentados nas Tabelas $1 \mathrm{e}$ 2, verifica-se que há possibilidade de agravos à saúde humana e ambiental, associados a importantes patógenos primários e secundários. A observação dos resultados indica ainda que diferentes microrganismos patogênicos apresentam capacidade de persistência ambiental, ressaltando, assim, os diferentes níveis de riscos à exposição biológica, quando prevalece o gerenciamento inadequado dos RSSS, no caráter intra e extra serviços de saúde.

A forma ou estágio ambiental apresentado por agentes patogênicos como E. coli, S. aureus, $M$. tuberculosis e Hepatite $\mathrm{B}$, com suas respectivas doses infectantes, destaca também outras possíveis rotas de transmissão de doenças, a partir do contato ou exposição aos materiais biológicos existentes nos RSSS.

Importante destacar que dentre esses microrganismos, a M. tuberculosis, causadora da doença infecciosa reemergente "tuberculose", e S. aureus apresentam uma forma de resistência ambiental bastante favorável à análise de risco individual, denominada aerossóis secundários. Os aerossóis, quando envolvidos em poeira ou muco, passam a ser protegidos da dessecação.

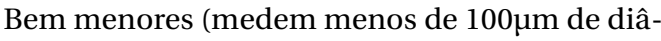
metro) e mais estáveis (flutuam no ar durante um intervalo de tempo mais ou menos longo), participam do processo de contaminação ambiental, possibilitando, assim, que os agentes infecciosos sejam transportados pelo ar de um local para outro (Rouquayrol \& Almeida Filho, 1999).

Para essa forma particular de veiculação de agentes, possibilitando à micropoeira em suspensão difundir-se a grandes distâncias, contendo o patógeno, há destaque principalmente para a $M$. tuberculosis, quando prevalecem condições ambientais adequadas ao material de eliminação (ex.: escarro), como o abrigo da luz.

Outro aspecto a ser observado está na resistência à dessecação apresentada pela enterobactéria $E$. coli. Para este agente, a resistência às condições estressantes, com possibilidade de ocasionar infecção, é mantida quando há presença de proteínas derivadas de fluidos corpóreos (sangue e derivados) (Hirai, 1991).

Nos resultados relacionados à definição dos prováveis indicadores de contaminação ambiental, apresentados nas Tabelas 3, 4 e 5, verifica-se que há destaque para importantes patógenos presentes nos RSSS, a partir da avaliação de riscos ambiental e individual associados aos agentes. 
Avaliação dos critérios adotados na seleção dos indicadores de contaminação ambiental (ambiente físico - água).

\begin{tabular}{|c|c|c|c|}
\hline $\begin{array}{l}\text { Indicador de } \\
\text { contaminação } \\
\text { ambiental }\end{array}$ & $\begin{array}{l}\text { Critério } \\
\text { (importância) }\end{array}$ & Descrição do critério & $\begin{array}{l}\text { Importância do } \\
\text { critério (peso) }\end{array}$ \\
\hline \multirow[t]{7}{*}{ Hepatite A } & A & Patógeno primário: ausência na microbiota normal humana & 2 \\
\hline & $\mathrm{B}$ & Contaminação ambiental & 5 \\
\hline & $\mathrm{C} 1$ & Não apresenta forma ou estágio de resistência nesse ambiente & 4 \\
\hline & $\mathrm{C} 2$ & Resistência a algumas substâncias desinfetantes (anti-sépticos) $\Rightarrow$ & \\
\hline & & Alterações nas suas características e resistência múltipla & \\
\hline & $\mathrm{D}$ & Água contaminada & 6 \\
\hline & $\mathrm{E}$ & Mecanismo de penetração no hospedeiro: ingestão (principal) & 6 \\
\hline \multirow[t]{6}{*}{ Escherichia coli } & A & Patógeno secundário: presença na microbiota normal humana & 2 \\
\hline & $\mathrm{B}$ & Contaminação ambiental & 5 \\
\hline & $\mathrm{C} 1$ & Não apresenta forma ou estágio de resistência nesse ambiente & 1 \\
\hline & $\mathrm{C} 2$ & Resistência a substâncias químicas $\Rightarrow$ Alterações nas suas características e resistência múltipla & \\
\hline & $\mathrm{D}$ & Água contaminada & 5 \\
\hline & $E$ & Mecanismo de penetração no hospedeiro: ingestão (principal) & 6 \\
\hline Clostridium & A & Patógeno secundário: presença na microbiota normal humana & 2 \\
\hline \multirow[t]{5}{*}{ perfringens } & $\mathrm{B}$ & Habitat natural e contaminação ambiental & 3 \\
\hline & $\mathrm{C} 1$ & Formação de endosporos $\Rightarrow$ Sobrevivência no ambiente por períodos longos & 5 \\
\hline & $\mathrm{C} 2$ & Resistência às substâncias tóxicas $\Rightarrow$ Alterações nas suas características e resistência múltipla & \\
\hline & $\mathrm{D}$ & Água contaminada & 5 \\
\hline & $\mathrm{E}$ & Mecanismo de penetração no hospedeiro: ingestão (possível) & 3 \\
\hline \multirow[t]{6}{*}{ Hepatite B } & A & Patógeno primário: ausência na microbiota normal humana & 2 \\
\hline & B & Contaminação ambiental & 3 \\
\hline & $\mathrm{C} 1$ & Estado inerte no ambiente e resistência em qualquer superfície & 4 \\
\hline & $\mathrm{C} 2$ & $\begin{array}{l}\text { Resistência a substâncias químicas (anti-sépticos) } \Rightarrow \text { Alterações nas suas características } \\
\text { e resistência múltipla }\end{array}$ & \\
\hline & $\mathrm{D}$ & Água contaminada & 2 \\
\hline & $E$ & Mecanismo de penetração no hospedeiro: ingestão (possível) & 1 \\
\hline
\end{tabular}

Critério: $A=$ Característica do agente, $B=$ Ocorrência no ambiente físico, $C=$ Forma ou estágio de resistência ambiental, $\mathrm{D}=$ Mecanismo de transmissão, $\mathrm{E}=$ Risco Individual.

Importância (peso): 0 = Sem importância alguma ou nulo, $1=$ Quase sem importância, $2=$ Pouco

importante, 3= Médio, 4 = Importante, 5 = Muito importante, 6 = Importantíssimo.

Pode-se observar que o critério relacionado à caraterística do agente (Critério $\mathrm{A})$, nas diferentes tabelas, foi considerado com pouca importância na seleção do prováveis indicadores. Atribui-se ao fato do agente ser considerado patógeno secundário (presente) ou patógeno primário (ausente) na microbiota normal humana, pode ser indiferente na avaliação como indicador, pois para causar a doença deve-se analisar a via de transmissão e a porta de entrada adequadas. Além disso, qualquer microrganismo pode causar doença, considerando os fatores anteriormente expostos e, principalmente, desde que haja comprometimento da resistência antiinfecciosa do hospedeiro.

Os demais critérios apresentaram relevância na valoração atribuída pelos especialistas, mas cada microrganismo indicador, associado a cada ambiente em análise, teve sua importância ou peso retratada de maneira diferenciada.
Na avaliação pelos especialistas, a M. tuberculosis representou o principal indicador na contaminação do ambiente físico - ar. Este patógeno foi destacado pela sua importância na saúde ocupacional. A capacidade da M. tuberculosis para iniciar uma infecção (dose infectante) é bastante reduzida, destacando-se assim a importância significativa quanto ao risco individual. A unidade de infecção dessa microbactéria pode ser considerada pequena, abrangendo uma partícula menor do que $5 \mu \mathrm{m}$ de diâmetro, suspensa no ar e contendo apenas um a três bacilos (Neves et al., 1983).

Outro aspecto a ser considerado na avaliação da M. tuberculosis, está na sua forma ou estágio de resistência ambiental, semelhante ao S. aureus. Entretanto, a principal diferença destacada para M. tuberculosis está no seu risco potencial de contaminação aerógena (produção de aerossóis $\Rightarrow$ bacilos suspensos no ar dentro de gotículas), mecanismo de transmis- 
Avaliação dos critérios adotados na seleção dos indicadores de contaminação ambiental (ambiente físico - solo).

\begin{tabular}{|c|c|c|c|}
\hline $\begin{array}{l}\text { Indicador de } \\
\text { contaminação } \\
\text { ambiental }\end{array}$ & $\begin{array}{l}\text { Critério } \\
\text { (importância) }\end{array}$ & Descrição do critério & $\begin{array}{l}\text { Importância do } \\
\text { critério (peso) }\end{array}$ \\
\hline \multirow[t]{6}{*}{ Hepatite B } & A & Patógeno primário: ausência na microbiota normal humana & 2 \\
\hline & B & Contaminação ambiental & 4 \\
\hline & $\mathrm{C} 1$ & Estado inerte no ambiente e resistência em qualquer superfície & 5 \\
\hline & $\mathrm{C} 2$ & $\begin{array}{l}\text { Resistência a algumas substâncias desinfetantes (anti-sépticos) } \Rightarrow \\
\text { Alterações nas suas características e resistência múltipla. }\end{array}$ & \\
\hline & $\mathrm{D}$ & Solo contaminado & 4 \\
\hline & $E$ & Mecanismo de penetração no hospedeiro: pele não íntegra (principal) & 5 \\
\hline \multirow[t]{6}{*}{ Escherichia coli } & A & Patógeno secundário: presença na microbiota normal humana & 2 \\
\hline & B & Contaminação ambiental & 5 \\
\hline & $\mathrm{C} 1$ & Resistência à dessecação na presença de proteínas derivadas de fluidos corpóreos & 4 \\
\hline & $\mathrm{C} 2$ & Resistência a substâncias químicas $\Rightarrow$ Alterações nas suas características e resistência múltipla & \\
\hline & $\mathrm{D}$ & Solo contaminado & 5 \\
\hline & $E$ & Mecanismo de penetração no hospedeiro: pele não íntegra (possível) & 2 \\
\hline \multirow[t]{6}{*}{ Enterococos } & A & Patógeno secundário: presença na microbiota normal humana & 2 \\
\hline & B & Contaminação ambiental & 5 \\
\hline & $\mathrm{C} 1$ & Formato de "coccus" $\Rightarrow$ Resistência à dessecação e maior tolerância às condições ambientais & 5 \\
\hline & $\mathrm{C} 2$ & $\begin{array}{l}\text { Resistência a substâncias químicas (antibióticos) fi Alterações nas suas características } \\
\text { e resistência múltipla }\end{array}$ & \\
\hline & $\mathrm{D}$ & Solo contaminado & 4 \\
\hline & $E$ & Mecanismo de penetração no hospedeiro: pele não íntegra (possível) & 2 \\
\hline Staphylococcus & A & Patógeno secundário: presença na microbiota normal humana & 2 \\
\hline \multirow[t]{5}{*}{ aureus } & B & Contaminação ambiental & 2 \\
\hline & $\mathrm{C} 1$ & Resistência à dessecação rápida & 5 \\
\hline & $\mathrm{C} 2$ & Resistência a antibióticos $\Rightarrow$ Alterações nas suas características e resistência múltipla & \\
\hline & $\mathrm{D}$ & Solo contaminado & 3 \\
\hline & $E$ & Mecanismo de penetração no hospedeiro: pele não íntegra (possível) & 4 \\
\hline Pseudomonas & A & Patógeno secundário: presença na microbiota normal humana & 2 \\
\hline \multirow[t]{5}{*}{ aeruginosa } & $\mathrm{B}$ & Habitat natural & 0 \\
\hline & $\mathrm{C} 1$ & $\begin{array}{l}\text { Capacidade de respirar anaerobicamente por utilizar o nitrato como receptor } \\
\text { de elétrons (anaeróbio facultativo) }\end{array}$ & 5 \\
\hline & $\mathrm{C} 2$ & $\begin{array}{l}\text { Resistência a antibióticos e anti-sépticos leves } \Rightarrow \text { Alterações nas suas características } \\
\text { e resistência múltipla }\end{array}$ & \\
\hline & $\mathrm{D}$ & Solo contaminado & 5 \\
\hline & $E$ & Mecanismo de penetração no hospedeiro: pele não íntegra (principal) & 6 \\
\hline
\end{tabular}

Critério: $A=$ Característica do agente, $B=$ Ocorrência no ambiente físico, $C=$ Forma ou estágio de resistência ambiental, $\mathrm{D}=$ Mecanismo de transmissão, $\mathrm{E}=$ Risco Individual.

Importância (peso): 0 = Sem importância alguma ou nulo, 1 = Quase sem importância, 2 = Pouco

importante, $3=$ Médio; 4 = Importante; 5 = Muito importante; 6 = Importantíssimo.

são utilizado pelo agente (aerossóis e poeira) e penetração no novo hospedeiro, tendo a inalação como forma principal de veiculação desse agente.

Ressaltando a utilização da M. tuberculosis como indicador de contaminação, Jonhson et al. (2000) apresentaram a transmissão deste bacilo em trabalhadores de uma estação de tratamento de resíduos de serviços de saúde. Esse relato epidemiológico, mostra a relevância da transmissão de agentes infecciosos considerando o estágio ambiental.

Pelos resultados apresentados na Tabela 4, verifica-se que patógenos como Hepatite A
(HAV) destacam-se como indicadores de contaminação mais significativos para o ambiente físico - água.

O HAV destacou-se como principal indicador devido a sua grande capacidade de transmissão pela água e, significativamente, em ambientes contaminados por excretas. Outro aspecto relacionado ao agente, reside na sua resistência a algumas substâncias desinfetantes (anti-sépticos) que pode lhe promover maior persistência ambiental.

Na avaliação feita pelos especialistas, foi verificada também que a importância do HAV como principal indicador de contaminação na 
água, contribui para associação da elevada incidência de doenças provocadas por hepatites viróticas.

Como segundo indicador de contaminação na água tem-se a E. coli, e evidencia a sua grande aplicação como indicador universal de qualidade sanitária. Entretanto, a presença de enterobactérias como E. coli na água, destaca a avaliação de risco ambiental na disposição final de RSSS no solo. Atribui-se a essa avaliação, o fato de que a enterobactéria $E$. coli pode conter plasmídios (moléculas portadoras de informação genética) de resistência a substâncias químicas (ex.: antibióticos), que podem ser transferíveis a cepas patogênicas, tornando-as resistentes (Roitman et al., 1987). Esse aspecto contribui para associação de risco ambiental relacionada a cepas patogênicas de E. coli, possivelmente existentes nos materiais biológicos de RSSS.

Para o Clostridium perfringens, a importância da sua valoração, apesar da freqüência moderada na água como habitat natural, deve-se, principalmente, a sua maior resistência às substâncias tóxicas, que lhe confere maior sobrevivência em águas poluídas (Roitman et al., 1987). É importante salientar que a forma ou estágio de resistência ambiental natural (formação de endosporos), contribui também para que esse patógeno permaneça viável na presença de substâncias tóxicas, que inibem o crescimento de outras espécies. Essa característica ambiental do C. perfringens favorece não só a sua utilização como indicador de contaminação antiga, mas contribui para sua definição como provável indicador de poluição em percolados nas áreas de disposição final de RSSS no solo.

Analisando os resultados expostos na Tabela 5, observa-se pela valoração consensual, que o vírus da Hepatite B (HBV) destaca-se como agente mais importante na contaminação do ambiente físico - solo.

A identificação do vírus HBV como principal microrganismo indicador, deve-se as suas características peculiares relacionadas ao potencial de risco ambiental (Critérios $\mathrm{B}$ e C), mecanismo de transmissão de doenças (Critério D) e destacado risco individual (Critério E).

Ressalta-se que o estado de inércia no ambiente, que pode conferir ao HBV resistência às mais adversas condições ambientais; resistência a algumas substâncias químicas e em qualquer superfície seca (à temperatura ambiente), por períodos longos sem a perda de sua infectividade (Bond et al., 1981; Trabulsi, 1998), constituem-se em aspectos ambientais de grande relevância na definição desse agente como principal indicador de contaminação no solo. Além disso, para o HBV, um indivíduo pode se contaminar, mesmo que o vírus esteja em concentração reduzida em amostras de sangue ou soro; no caso de inoculação percutânea ou ainda por uma exposição inadvertida por meio de coortes e arranhões existente na pele ou mucosa (Yoshida, 1996). Destacando assim, o risco elevado de acidentes com materiais perfurocortantes contaminados, que pode resultar em uma infecção pelo HBV.

É importante salientar a existência de estudos sobre a presença de patógenos oportunistas nos líquidos percolados da disposição final de RSSS, que revelam microrganismos indicadores de contaminação ambiental como a P. aeruginosa, S. aureus, E. fecais e C. perfringens (Bidone et al., 2000; Boening \& Vasconcelos, 1997).

O presente trabalho apresentou um conjunto de possíveis indicadores de contaminação ambiental. Contudo, a realização de monitorização ambiental em áreas de disposição final de RSSS, poderá contribuir para validar ou não os indicadores propostos (Silva, 2001).

\section{Agradecimentos}

Agradecemos as valiosas contribuições dos professores Dra. Celeste Aída, Dr. Cleudson Castro e Dra. Lucrécia Ramos, da Universidade de Brasília e à enfermeira Rejane Alves, do Centro Nacional de Epidemiologia, Fundação Nacional de Saúde, Ministério da Saúde, pela colaboração na etapa de aplicação do método. 


\section{Referências}

BIDONNE, F. R. A.; SOUZA, L. F. \& MACHADO, R. M., 2000. Microrganismos de interesse em saúde pública pesquisados em percolado de aterro sanitário de codisposição de resíduos sólidos de serviços de saúde com resíduos sólidos urbanos. In: Congreso Interamericano de Ingeniería Sanitaria y Ambiental, Anales, CD-ROM. Porto Alegre: Asociación Interamericana de Ingeniería Sanitaria y Ambiental.

BOENING, D. W. \& VASCONCELOS, G. J., 1997. Persistence and antibiotic immunity of bacteria from a wetland used as a medical waste landfill. Journal of Environmental Health, 59:6-13.

BOND, W. W.; FAVERO, M. S.; PETERSEN, N. J.; GRAVELLE, C. R.; EBERT, J. W. \& MAYNARD, J. E., 1981. Survival of hepatitis B virus after drying and storage for one week. Lancet, 1:550-551.

CETESB (Companhia de Tecnologia de Saneamento Ambiental do Estado de São Paulo), 1983. Resíduos hospitalares. In: XII Congresso Brasileiro de Engenharia Sanitária e Ambiental, Resumos, pp. 176-202. Santa Catarina: Associação Brasileira de Engenharia Sanitária e Ambiental.

COLLINS, C. H. \& KENNEDY, D. A., 1987. Microbiological hazards of occupational needlestick and sharps injuries. Journal of Applied Bacteriology, 62:385-402.

FERREIRA, J. A., 1995. Resíduos sólidos e lixo hospitalar: Uma discussão ética. Cadernos de Saúde Pública, 11:314-320.

GOICOECHEA, A.; HANSEN, D. R. \& DUCKSTEIN, L., 1982. The Nominal Group Technique In: Multiobjective Decision Analysis with Engineering and Business Applications (A. Goicoechea, D. R. Hansen \& L. Duckstein, ed.), pp. 361-363, New York: Jonh Wiley \& Sons.

HAAS, C. N.; ANOTAI, J. \& ENGELBRECHT, R. S., 1996. Monte Carlo assessment of microbial risk associated with landfilling of fecal material. Water Environment Research, 68:1123-1131.

HIRAI, Y., 1991. Survival of bacteria under dry conditions: From a viewpoint of nosocomial infection. Journal of Hospital Infection, 19:191-200.

JONHSON, R. K.; BRADEN, C. R.; CAIRNS, K. L.; FIELD, K. W.; COLOMBEL, A. C.; YANG, Z.; WOODLEY, C. L.; MORLOCK, G. P.; WEBER, A. M.; BOUDREAU, A. Y.; BELL, T. A.; ONORATO, I. M.; VALWAY, S. E. \& STEHR-GREEN, P. A., 2000. Transmission of Mycobacterium tuberculosis from medical waste. JAMA, 284:1683-1688.

MOREL, M. M. O. \& BERTUSSI FILHO, L. A., 1997. Resíduos de serviços de saúde. In: Infecções Hospitalares: Prevenção e Controle (E. A. C. Rodrigues, J. S. Mendonça, J. M. B. Amarante, M. B. Alves Filho, R. S. Grinbaum \& R. Richtmann, org.), pp. 519-534, São Paulo: Editora Sarvier.
NEVES, J. S.; DETTONI, V. V.; PISSINALI, C. S. \& PEÇANHA, P. M., 1983. Tuberculose. In: Diagnóstico e Tratamento das Doenças Infectuosas e Parasitárias (J. Neves, org.), pp. 496-524, Rio de Janeiro: Guanabara Koogan.

PHILLIPS, G., 1999. Microbiological aspects of clinical waste. Journal of Hospital Infection, 41:1-6.

PRUSS, A.; GIROULT, E. \& RUSHBROOK, P., 1999. Health impacts of health-care waste. In: Safe Management of Wastes from Health-Care Activities (A. Pruss, E. Giroult \& P. Rushbrook, ed.), pp. 20-30, Geneva: World Health Organization.

ROITMAN, I.; TRAVASSOS, L. R. \& AZEVEDO, J. L., 1987. Tratado de Microbiologia. São Paulo: Editora Manole.

ROUQUAYROL, M. Z. \& ALMEIDA FILHO, N., 1999. Epidemiologia \& Saúde. Rio de Janeiro: Editora Medsi.

RUTALA, W. A.; ODETTE, R. L. \& SAMSA, G. P., 1989. Management of infectious waste by US hospital. JAMA, 262:1635-1640.

SILVA, A. C. N., 2001. Indicadores de Contaminação Ambiental e Diretrizes Técnicas para Disposição Final de Resíduos Sólidos de Serviços de Saúde: Uma Abordagem Multidisciplinar. Dissertação de Mestrado, Brasília: Departamento de Engenharia Civil e Ambiental, Faculdade de Tecnologia, Universidade de Brasília.

SILVA, L. T. C. V., 1993. Caracterização do Resíduo Hospitalar: Uma Inferência à Patogenicidade. Dissertação de Mestrado, São Paulo: Faculdade de Engenharia Civil, Universidade Estadual de Campinas.

TOMMASI, L. R., 1994. Estudo de Impacto Ambiental. São Paulo: Companhia de Tecnologia e Saneamento Ambiental do Estado de São Paulo.

TRABULSI, L. R., 1998. Microbiologia. São Paulo: Editora Atheneu.

TURNBERG, W. L. \& FROST, F., 1990. Survey of occupational exposure of waste industry workers to infectious waste in Washington State. American Journal of Public Health, 80:1262-1265.

YOSHIDA, C. F. T., 1996. Hepatite B como saúde ocupacional. In: Biossegurança: Uma Abordagem Multidisciplinar (P. Teixeira \& S. Valle, org.), pp. 257-272, Rio de Janeiro: Editora Fiocruz.

ZANON, U., 1990. Riscos infecciosos imputados ao lixo hospitalar: Realidade epidemiológica ou ficção sanitária? Revista da Sociedade Brasileira de Medicina Tropical, 23:163-170.

Recebido em 13 de dezembro de 2001

Aprovado em 1 de abril de 2002 